\title{
Perencanaan Pengembangan Sistem Distribusi Instalasi Pengolahan Air (IPA) Kedunguling Kecamatan Candi Kabupaten Sidoarjo Jawa Timur
}

\author{
Oleh : Muhammad Ali Abdur Rosyid *) dan Indah Nurhayati **)
}

\begin{tabular}{|c|c|}
\hline \multicolumn{2}{|c|}{ Abstrak } \\
\hline $\begin{array}{l}\text { Cakupan pelayanan PDAM "Delta } \\
\text { dalah } 28,13 \% \text { sedangkan untuk ke } \\
\text { elayanan tersebut masih jauh dari target } \mathrm{r} \\
\text { edesaan. Maka perlu diadakan evaluasi ja } \\
\text { istribusi Instalasi Pengolahan Air (IPA) Ke } \\
\text { terencanakan jaringan distribusi baru de } \\
\text { istribusi. } \\
\text { Penelitian bertujuan untuk menge } \\
\text { eerencanakan sistem distribusi baru denga } \\
\text { lenggunakan perhitungan komputer melalui } \\
\text { Dari hasil penelitian dapat disimpulke } \\
\text { dalah sebesar } 214,02 \text { I/dt sehingga pada to } \\
\text { laksimal. Untuk analisa jaringan eksisting, } \\
\text { aitu dibawah } 0,3 \text { m/dt. Sedangkan untuk } \\
\text { tmosper (atm) masih sesuai dengan kriteria } \\
\text { Maka untuk melayani kebutuhan } \\
\text { iambilkan dari pembangunan Proyek Um } \\
\text { iringan diperlukan penggantian pompa dan }\end{array}$ & $\begin{array}{l}\text { Sidoarjo sampai Bulan Maret Tahun } 2011 \\
\text { Candi baru mencapai } 20,89 \% \text {. Cakupan } \\
\text { yaitu } 80 \% \text { untuk perkotaan dan } 60 \% \text { untuk } \\
\text { distribusi yang sudah ada khususnya sistem } \\
\text { g Kecamatan Candi Kabupaten Sidoarjo dan } \\
\text { menggunakan Sistem Pemodelan Jaringan } \\
\text { sistem distribusi yang sudah ada dan } \\
\text { ekatan Sistem Pemodelan Jaringan Distribusi } \\
\text { m Watercad. } \\
\text { a debit air yang dibutuhkan pada tahun } 2022 \\
13 \text { tingkat pelayanan IPA Kedunguling sudah } \\
\text { itemukan kecepatan aliran yang relatif rendah } \\
\text { n terendah di titik terjauh yaitu sebesar } 4,1 \\
\text { tribusian air minum. } \\
\text { npai tahun } 2022 \text {, kekurangan debit dapat } \\
\text { I sedangkan untuk pemerataan tekanan di } \\
\text { mpa yang berkapasitas } 120 \text { I/dt dengan head } \\
50 \text { mm dari reservoir ke arah kota melalui } \\
\text { Jaru diameter } 250 \text { mm dari reservoir ke arah } \\
\text { Cad, IPA Kedunguling }\end{array}$ \\
\hline $\begin{array}{l}\text { PENDAHULUAN } \\
\text { Dewasa ini kebutuhan air bersih } \\
\text { semakin meningkat. Hal ini disebabkan } \\
\text { bukan saja akibat pertumbuhan penduduk } \\
\text { dengan segala aktivitasnya, akan tetapi juga } \\
\text { seiring dengan meningkatnya status sosial } \\
\text { dan ekonomi masyarakat setempat. } \\
\text { Kesadaran masyarakat akan pentingnya air } \\
\text { bersih dengan pelayanan yang baik, dari } \\
\text { segi kuantitas, kualitas maupun } \\
\text { kontinuitasnya terus meningkat. } \\
\text { Sampai sekarang masih ada daerah } \\
\text { layanan Perusahaan Daerah Air Minum } \\
\text { (PDAM) "Delta Tirta" Kabupaten Sidoarjo } \\
\text { yang belum mampu diberikan pelayanan } \\
\text { dalam jumlah yang cukup selama } 24 \text { jam } \\
\text { dengan kualitas seperti yang diharapkan. } \\
\text { Cakupan pelayanan PDAM "Delta } \\
\text { Tirta" Sidoarjo sampai Bulan Maret Tahun } \\
2011 \text { adalah } 28,13 \% \text { sedangkan untuk } \\
\text { kecamatan Candi baru mencapai } 20,89 \% \text {. } \\
\text { Cakupan pelayanan tersebut masih jauh } \\
\text { dari target nasional yaitu } 80 \% \text { untuk } \\
\text { perkotaan dan } 60 \% \text { untuk pedesaan. } \\
\text { Disamping berbagai kendala yang ada } \\
\text { antara lain keterbatasan produksi, } \\
\text { keterbatasan prasarana distribusi serta } \\
\text { pendanaan, PDAM "Delta Tirta" Kabupaten }\end{array}$ & $\begin{array}{l}\text { Sidoarjo secara bertahap telah membangun } \\
\text { sistem penyediaan air bersih dengan } \\
\text { membangun jaringan distribusi baru dan } \\
\text { memperbaiki jaringan distribusi yang sudah } \\
\text { ada sehingga membantu pemerataan } \\
\text { distribusi. Banyak usaha yang sudah } \\
\text { dilakukan tetapi belum mencukupi } \\
\text { kebutuhan sesuai yang diharapkan. } \\
\text { Untuk menambah kapasitas air sesuai } \\
\text { kebutuhan, PDAM "Delta Tirta" Kabupaten } \\
\text { Sidoarjo merencanakan pembangunan } \\
\text { Proyek Umbulan II yang mengalirkan air } \\
\text { bersih dari mata air Umbulan di Kabupaten } \\
\text { Pasuruan ke Kabupeten Sidoarjo. Dari } \\
\text { rencana tersebut, PDAM "Delta Tirta" } \\
\text { Kabupaten Sidoarjo mendapatkan debit } \\
\text { sebesar 1.300 liter/detik yang dibagi } \\
\text { menjadi delapan off take (titik pengambilan), } \\
\text { yaitu off take Jabon, off take Porong, off } \\
\text { take Tanggulangin, off take Candi, off take } \\
\text { Sidoarjo, off take Buduran, off take } \\
\text { Gedangan dan off take Waru. Masing } \\
\text { masing off take mempunyai demand } \\
\text { (kebutuhan) yang berbeda disesuaikan } \\
\text { dengan kondisi jaringan distribusi yang } \\
\text { sudah ada (existing). } \\
\text { *) Mahasiswa Teknik Lingkungan } \\
* \text { *)Dosen Teknik Lingkungan } \\
\text { Universitas PGRI Adi Buana Surabaya }\end{array}$ \\
\hline
\end{tabular}


Untuk merencanakan sistem perpipaan dalam pelayanan air bersih perlu dibuat pemodelan. Simulasi sistem distribusi merupakan proses pemodelan perilaku sistem distribusi dengan pendekatan matematis untuk mendapatkan kondisi yang hampir sama pada kondisi sebenarnya. Dari proses simulasi dengan pemodelan sistem jaringan distribusi akan mempermudah kita dalam :

1. Memperkirakan respon sistem distribusi eksisting terhadap kondisi yang akan datang.

2. Dapat dilakukan antisipasi terhadap kondisi-kondisi yang nantinya terjadi pada suatu sistem, baik sistem eksisting maupun yang akan direncanakan.

3. Mempermudah kita dalam melakukan evaluasi dan pengembangan sistem jaringan.

4. Mempermudah dalam pembuatan zonazona pelayanan didasarkan pada kondisi-kondisi tertentu yang akan lebih mudah diperhitungkan dengan adanya model jaringan distribusi yang akan dibuat.

Dalam pembuatan model suatu sistem distribusi membutuhkan beberapa tahapan sebelum model tersebut dapat dipakai untuk tujuan tersebut di atas. Pemodelan ini harus didahului beberapa tahap persiapan yang menunjang dalam pembuatan suatu model, seperti pengumpulan data, pemilihan program pemodelan, pengecekan data dan lain-lain. Hal ini dimaksudkan agar pemodelan yang kita lakukan nantinya benar-benar akan mendekati kondisi sebenarnya dari suatu jaringan distribusi. Keakurasian model sistem jaringan distribusi yang akan dibuat sangat tergantung dari data yang diperoleh, data yang diperoleh semakin detail dan baik maka simulasi model yang akan dibuat akan semakin mendekati kondisi nyata dari sistem di lapangan. Untuk itu diperlukan database tentang jaringan distribusi secara lengkap akan sangat membantu dalam melakukan analisa dan evaluasi jaringan distribusi.
Beberapa komponen yang perlu disiapkan sebelum melakukan pemodelan sistem distribusi antara lain :

1. Peta dan data pipa jaringan distribusi dibuat model (panjang pipa, diameter pipa dan jenis pipa).

2. Data tentang kebutuhan air, kebutuhan air ini harus dilakukan analisa untuk menentukan kelayakan jaringan terhadap debit air yang diperlukan oleh konsumen. Kebutuhan air yang harus didata meliputi kebutuhan air tiap-tiap titik tapping sesuai dengan wilayah pelayanan, sehingga model yang dibuat nantinya dapat mewakili penyebaran kebutuhan air sesuai dengan jumlah pelanggan dan lokasi pelanggan. Analisa kebutuhan air ini meliputi :

a. Perhitungan analisa kebutuhan air pada sistem jaringan perpipaan distribusi eksisting.

b. Perhitungan analisa kebutuhan air jaringan perencanaan, yang terdiri dari eksisting dan kebutuhan air rencana. Data kebutuhan air ini harus meliputi kebutuhan air untuk domestik dari pelanggan rumah, non domestik (industri, niaga, komersial dan lain-lain) juga air yang hilang sebagai tingkat kebocoran. Selain itu juga perlu memperhatikan faktor kebutuhan air seperti faktor jam puncak, faktor hari maksimum dan sebagainya.

3. Menentukan batasan-batasan hidrolis dalam simulasi yang akan dibuat, misalnya:

a. Kehilangan tekanan maksimal yang diijinkan adalah 10 meter per 1.000 meter.

b. Kecepatan minimum dalam pipa 0,3 meter/detik.

c. Kecepatan maksimum dalam pipa 3 meter/detik.

d. Tekanan kerja maksimum dalam pipa 8 atm atau 8,106 bar atau 82,658196 meter kolom air (mka).

e. Tekanan kerja minimum dalam pipa di titik terjauh 1 atm atau 1,01325 bar atau 10,332275 meter kolom air (mka).

Batasan-batasan ini yang akan menjadi acuan kita dalam melakukan suatu evaluasi model jaringan yang akan dibuat. 
Ketika dalam model yang dibuat nantinya banyak output data yang tidak masuk dalam kriteria ini, maka model yang sudah dibuat harus dilakukan perbaikan-perbaikan dengan misalnya melakukan simulasi terhadap diameter pipa, pengoperasian valve dan sebagainya, sampai model kita sesuai dengan batasan yang kita buat. Adapun batasan-batasan yang kita buat tersebut harus sesuai dengan kriteriakriteria yang ada misalnya dari batasan karakteristik pipa dan lain sebagainya.
Berdasarkan Mays (1999), WaterCad adalah peraga sistem distribusi air yang dikembangkan oleh Water Supply and Water Resources Division pada U.S. Environmental Protection Agency. Program ini menampilkan simulasi pengembangan hidrolis dan kualitas air dengan jaringan pipa bertekanan dan didesain untuk menjadi alat penelitian yang meningkatkan pemahaman mengenai masalah-masalah pada pendistribusian air minum.

Adapun data yang diperlukan untuk membuat analisa model perpipaan menggunakan pogram WaterCAD adalah seperti tabel 1 berikut ini:

Tabel 1. Data yang diperlukan pada program WaterCad

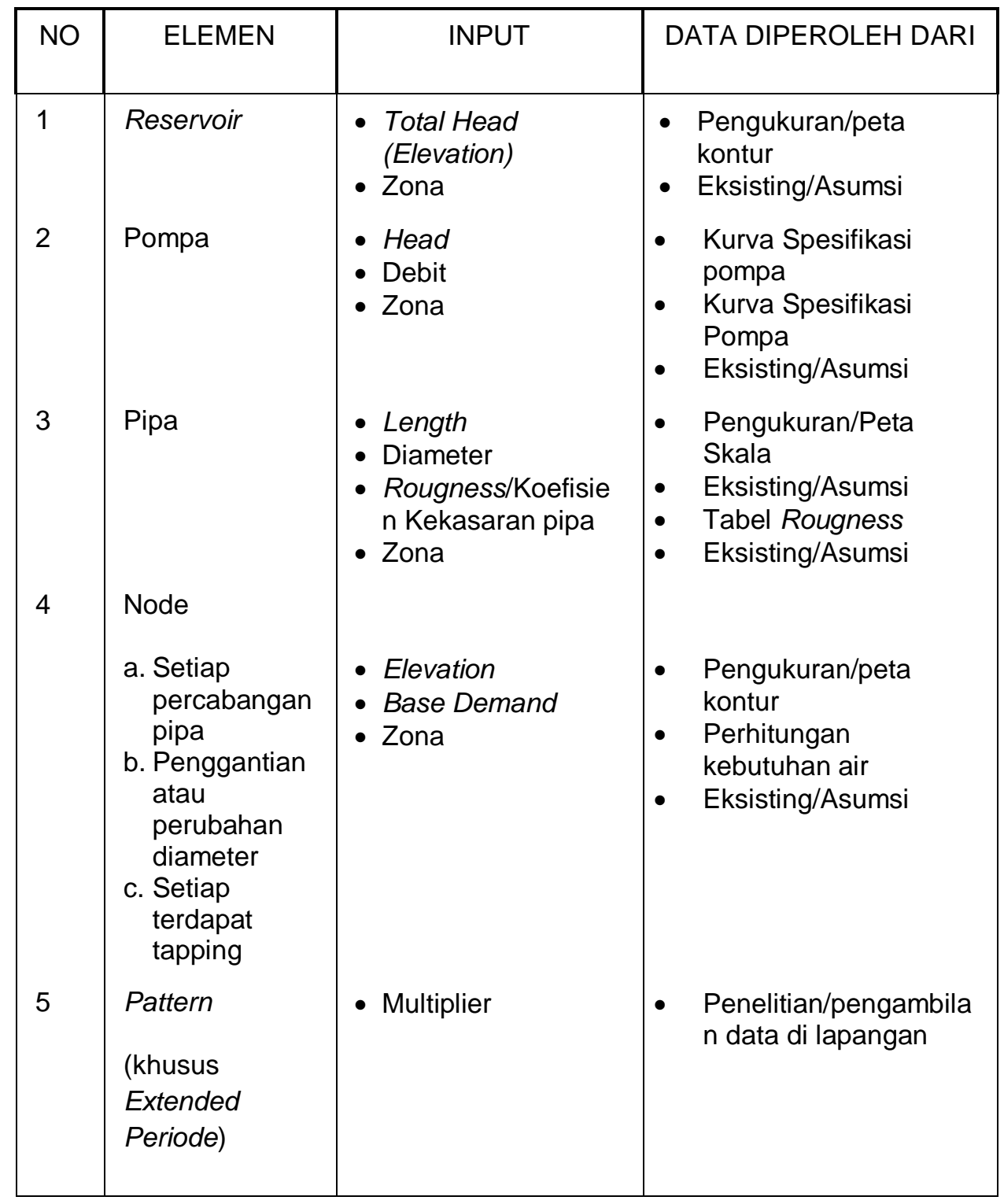


Untuk mengatasi permasalahan ini, maka PDAM "Delta Tirta" Kabupaten Sidoarjo perlu mengevaluasi jaringan distribusi yang sudah ada dan merencanakan jaringan distribusi baru dengan menggunakan Sistem Pemodelan Jaringan Distribusi. Pemodelan Jaringan Distribusi ini bertujuan untuk mengoptimalkan jaringan distribusi existing maupun jaringan distribusi baru yang akan di bangun.

\section{Rumusan Masalah}

Rumusan masalah dalam kajian ini adalah : Sudah optimalkah jaringan distribusi existing tahun 2011 dan berapa panjang dan diameter pipa yang dibutuhkan untuk pengembangan jaringan distribusi baru?

\section{Tujuan Penelitian}

Mengkaji optimal tidaknya jaringan distribusi existing tahun 2011 dan mengkaji panjang dan diameter pipa yang dibutuhkan untuk pengembangan jaringan distribusi baru.

\section{Metode Penelitian}

Metode penelitian dilakukan dengan pendekatan Sistem Pemodelan Jaringan Distribusi menggunakan perhitungan komputer melalui program Watercad.

\section{Analisis dan Pembahasan}

Data hasil penelitian yang diperoleh dengan cara observasi dan wawancara di sajikan sebagai berikut ini

1. Sumber air baku IPA Kedunguling berasal dari Avfoer Kedunguling.

2. IPA Kedunguling mempunyai 2 treatment yang masing-masing berkapasitas $50 \mathrm{l} / \mathrm{dt}$ sehingga maksimal debit yang keluar dari IPA Kedunguling sebesar $100 \mathrm{l} / \mathrm{dt}$.

3. Cakupan pelayanan di wilayah kecamatan Candi pada bulan Maret 2012 baru mencapai 5.247 sambungan rumah dari 150.728 penduduk atau sekitar $20,89 \%$.

Data jumlah penduduk dari tahun $1980 \mathrm{~s} / \mathrm{d} 2010$ dengan tingkat pertumbuhan rata-rata sebesar $3,8461 \%$ yang diperoleh dari dari kantor BPS Sidoarjo tahun 2011 seperti tampak pada tabel 1 berikut :

Tabel 2

Luas Wilayah $\left(\mathrm{Km}^{2}\right)$ dan Jumlah Penduduk Menurut Kecamatan

Hasil Sensus Penduduk 1980, 1990, 2000 dan 2010

\begin{tabular}{|c|l|c|c|c|c|c|}
\hline \multicolumn{2}{|c|}{ Kecamatan } & \multirow{2}{*}{$\begin{array}{c}\text { Luas } \\
\text { Wilayah }\end{array}$} & \multicolumn{4}{c|}{ Tahun } \\
\cline { 4 - 7 } & & 1980 & 1990 & 2000 & 2010 \\
\hline & & $(2)$ & $(3)$ & $(4)$ & $(5)$ & $(6)$ \\
1. & Sidoarjo & 62,56 & 80.074 & 101.586 & 146.615 & 194.051 \\
2. & Buduran & 41,03 & 31.940 & 44.844 & 65.164 & 92.334 \\
3. & Candi & 40,67 & 46.832 & 60.794 & 92.897 & 145.146 \\
4. & Porong & 29,82 & 49.979 & 58.933 & 69.337 & 65.909 \\
5. & Krembung & 29,55 & 41.407 & 45.978 & 53.039 & 58.358 \\
\end{tabular}


Muh. Ali Abdur R dan Indah Nurhayati : Perencanaan Pengembangan Sistem Distribusi Instalasi Pengolahan Air (IPA) Kedunguling Wilayah Kecamatan Candi Kabupaten Sidoarjo

\begin{tabular}{|c|l|c|c|c|c|c|} 
6. & Tulangan & 31,21 & 49.983 & 58.327 & 67.308 & 87.422 \\
7. & Tanggulangin & 32,29 & 46.484 & 56.597 & 71.149 & 84.580 \\
9. & Jabon & 81,00 & 69.167 & 42.471 & 47.683 & 49.989 \\
10. & Kalongbendo & 31,40 & 40.771 & 47.441 & 57.357 & 66.865 \\
11. & Wonoayu & 33,92 & 42.610 & 50.530 & 61.666 & 72.009 \\
12. & Tarik & 36,06 & 39.655 & 46.472 & 53.645 & 60.977 \\
13. & Prambon & 34,23 & 46.154 & 53.212 & 60.924 & 68.336 \\
14. & Taman & 31,54 & 76.585 & 122.393 & 176.704 & 212.857 \\
15. & Waru & 30,32 & 54.801 & 139.050 & 210.426 & 231.298 \\
16. & Gedangan & 24,06 & 43.229 & 73.244 & 106.630 & 132.847 \\
17. & Sedati & 79,43 & 31.580 & 45.458 & 67.469 & 92.468 \\
18. & Sukodono & 32,68 & 36.921 & 46.892 & 66.430 & 111.121 \\
\hline & Jumlah & 714,27 & 889.160 & 1.169 .457 & 1.565 .015 & 1.947 .262 \\
\hline
\end{tabular}

Sumber data: BPS Sidoarjo tahun 2011

\section{Proyeksi Penduduk}

Perkiraan penduduk merupakan salah satu faktor guna menentukan besarnya kebutuhan sistem penyediaan air bersih yang direncanakan. Proyeksi perkembangan jumlah penduduk
Kecamatan Candi dihitung bedasarkan metode geometri, hal ini dijadikan pedoman dalam perencanaan pendistribusian air bersih untuk tahun yang direncanakan. Seperti tampak pada tabel 3 berikut.

Tabel 3 Rata-rata Pertumbuhan Penduduk Kecamatan Candi

\begin{tabular}{|l|c|c|c|c|}
\hline \multicolumn{1}{|c|}{ Tahun } & 1980 & 1990 & 2000 & 2010 \\
\hline Jumlah Penduduk & 46.832 & 60.794 & 92.897 & 145.146 \\
Pertumbuhan (\%) & & 2,6436 & 4,3312 & 4,5636 \\
\hline Pertumbuhan rata-rata (\%) & & & $\mathbf{3 , 8 4 6 1}$ \\
\hline
\end{tabular}

Sumber data: BPS Sidoarjo tahun 2011, hasil perhitungan excel

Dari hasil perhitungan di atas, dapat diketahui bahwa laju pertumbuhan penduduk Kecamatan Candi sebesar
$3,8461 \%$ pertahun, maka dapat dihitung proyeksi jumlah penduduk sampai tahun 2022 seperti pada tabel 4 berikut. 
Tabel 4

Perhitungan Proyeksi Jumlah Penduduk Sampai Tahun 2022

\begin{tabular}{|c|c|c|c|}
\hline Tahun & $\begin{array}{c}\text { Tahun } \\
\text { ke- }\end{array}$ & $\mathrm{R}$ & $\begin{array}{c}\text { Jumlah } \\
\text { penduduk }\end{array}$ \\
\hline 2010 & 0 & 0,0385 & 150.728 \\
2011 & 1 & 0,0385 & 156.526 \\
2012 & 2 & 0,0385 & 162.546 \\
2013 & 3 & 0,0385 & 168.797 \\
2014 & 4 & 0,0385 & 175.290 \\
2015 & 5 & 0,0385 & 182.031 \\
2016 & 6 & 0,0385 & 189.033 \\
2017 & 7 & 0,0385 & 196.303 \\
2018 & 8 & 0,0385 & 203.853 \\
2019 & 9 & 0,0385 & 211.693 \\
2020 & 10 & 0,0385 & 219.835 \\
2021 & 11 & 0,0385 & 228.290 \\
2022 & 12 & & \\
\hline Sumber data: Hasil perhitungan excel
\end{tabular}

\section{Proyeksi Kebutuhan air bersih}

Berdasarkan proyeksi penduduk Kecamatan Candi yang akan dilayani air bersih pada tahun 2022 sebesar 228.290 jiwa dengan asumsi pelayanan penduduk $25 \%$ dan kriteria perencanaan yang diambil sebesar $150 \mathrm{l} / \mathrm{org} / \mathrm{hr}$, maka kebutuhan air domestik dapat dihitung sebagai berikut :

a. Kebutuhan air domestik

$$
\begin{aligned}
\boldsymbol{Q d} & =\boldsymbol{P} \times \boldsymbol{Q} \times \mathbf{P} \\
& =228.290 \mathrm{jiwa} \times 150 \mathrm{l} / \mathrm{org} / \mathrm{hr} \times 25 \% \\
& =99,08 \mathrm{I} / \mathbf{d t}
\end{aligned}
$$

b. Kebutuhan air non-domestik

Berdasarkan data dari bagian litbang PDAM Delta Tirta Sidoarjo, untuk kebutuhan air non domestik diasumsikan sebesar $20 \%$ dari kebutuhan air domestik, maka kebutuhan air nondomestik dapat dihitung sebagai berikut :

Qnd $=20 \% \times Q d$

$$
\begin{aligned}
& =20 \% \times 99,08 \mathrm{l} / \mathrm{dt} \\
& =19,82 \mathrm{l} / \mathbf{d t}
\end{aligned}
$$


c. Total kebutuhan air Jadi untuk perhitungan total kebutuhan air dapat dihitung sebagai berikut :

$$
\begin{aligned}
\text { Qtot }=Q d+ & \text { Qnd } \\
& =99,08 \mathrm{l} / \mathrm{dt}+19,82 \mathrm{l} / \mathrm{dt} \\
& =\mathbf{1 1 8}, 90 \mathrm{l} / \mathbf{d t}
\end{aligned}
$$

d. Kehilangan air

Berdasarkan data dari bagian litbang PDAM Delta Tirta Sidoarjo, untuk kehilangan air diasumsikan sebesar 20\% dari total kebutuhan air. Sehingga kehilangan air yang terjadi dapat dihitung sebagai berikut :

$$
\begin{aligned}
\text { Kehilangan air } \quad & \text { Qtot } \times 20 \% \\
& =118,90 \mathrm{I} / \mathrm{dt} \times 20 \% \\
& =\mathbf{2 3}, \mathbf{7 8} \mathrm{I} / \mathbf{d t}
\end{aligned}
$$

e. Kebutuhan air rata-rata harian (Qrh)

Kebutuhan air rata-rata harian adalah banyaknya air yang diperlukan untuk memenuhi kebutuhan domestik, non domestik dan ditambah dengan kehilangan air. Sehingga kebutuhan air rata-rata harian dapat dihitung sebagai berikut :

$$
\begin{aligned}
\text { Qrh } & =\text { Qd }+ \text { Qnd }+ \text { kehilangan air } \\
& =99,08 \mathrm{I} / \mathrm{dt}+19,82 \mathrm{l} / \mathrm{dt}+23,78 \mathrm{I} / \mathrm{dt} \\
& =142,68 \mathrm{I} / \mathbf{d t}
\end{aligned}
$$

f. Kebutuhan air hari maksimum (Qhm) Kebutuhan air hari maksimum adalah banyaknya air yang diperlukan terbesar pada suatu hari pada satu tahun dan berdasarkan pada Qrh. Untuk menghitung Qhm diperlukan faktor fluktuasi kebutuhan air maksimum yang diasumsikan sebesar 1,1.

$$
\begin{aligned}
\text { Qhm } & =\text { Fhm } \times \text { Qrh } \\
& =1,1 \times 142,68 \mathrm{l} / \mathrm{dt} \\
& =\mathbf{1 5 6 , 9 5} \mathrm{l} / \mathbf{d t}
\end{aligned}
$$

g. Kebutuhan air jam maksimum (Qjm) Kebutuhan air jam maksimum adalah banyaknya kebutuhan air terbesar pada saat jam tertentu dalam satu hari. Diasumsikan faktor jam maksimum sebesar 1,5.

$$
\begin{aligned}
\text { Qjm } & =\text { Fjm } \times \text { Qrh } \\
& =1,5 \times 142,68 \mathrm{I} / \mathrm{dt} \\
& =\mathbf{2 1 4 , 0 2} \mathbf{I} / \mathbf{d t}
\end{aligned}
$$

Dari perhitungan diatas maka dapat diketahui kebutuhan air bersih Kecamatan Candi sampai tahun 2022 sebesar 214,021 l/dt sedangkan kapasitas terpasang IPA Kedunguling sebesar $100 \mathrm{l} / \mathrm{dt}$ sehingga dapat diketahui bahwa pada tahun 2014 sampai tahun 2022 IPA Kedunguling mengalami kekurangan debit antara $8 \mathrm{l} / \mathrm{dt}$ sampai $114 \mathrm{l} / \mathrm{dt}$.

\section{Eksisting Kedunguling \\ pelayanan \\ IPA} Pelayanan eksisting IPA Kedunguling dapat dievaluasi melalui program waterCad sehingga dapat diketahui kecepatan aliran dalam pipa antara 0,01-1,14 $\mathrm{m} / \mathrm{s}$ dan sisa tekan minimum pada ujung terjauh sebesar 4,1 atm Dengan pemakaian pompa kapasitas 500 I.s dan head 60 atm.

\section{Rencana pelayanan IPA Kedunguling tahun 2022}

Rencana Pelayanan IPA Kedunguling pada tahun 2022 dengan kebutuhan air tiap node dapat dievaluasi melalui program waterCad sehingga dapat diketahui kecepatan aliran dalam pipa sebesar 0,31-2,19 m/s dan sisa tekan minimum pada ujung terjauh 1,1 atm. Dengan pemakaian pompa kapasitas 120 I.s dan head $80 \mathrm{~atm}$. 


\section{KESIMPULAN}

1. Debit pelayanan saat ini Berdasarkan data PDAM "Delta Tirta" Kabupaten Sidoarjo bahwa IPA Kedunguling mempunyai 2 (dua) buah Water Treatment Plant (WTP) masingmasing berkapasitas $50 \mathrm{l} / \mathrm{dt}$ sehingga maksimal debit yang keluar dari IPA Kedunguling sebesar $100 \mathrm{l} / \mathrm{dt}$ yang berasal dari Avfoer Kedunguling.

2. Debit pelayanan perencanaan

Berdasarkan hasil perhitungan debit air yang dibutuhkan pada tahun 2022 adalah sebesar 214,02 l/dt. Jika dengan debit air yang disediakan oleh IPA Kedunguling saat ini yaitu $100 \mathrm{l} / \mathrm{dt}$ maka pada tahun 2011 sampai 2013 tingkat pelayanan IPA Kedunguling sudah maksimal, hal ini diketahui karena pada tahun 2011 sampai tahun 2013 IPA Kedunguling mengalami kelebihan debit antara $2 \mathrm{l} / \mathrm{dt}$ sampai $31 \mathrm{l} / \mathrm{dt}$. Sedangkan pada tahun 2014 sampai tahun 2022 tingkat pelayanan IPA Kedunguling sudah tidak maksimal hal ini diketahui karena pada tahun 2014 sampai tahun 2022 IPA Kedunguling mengalami kekurangan debit antara $8 \mathrm{l} / \mathrm{dt}$ sampai $114 \mathrm{l} / \mathrm{dt}$.

3. Sistem eksisting

Berdasarkan perhitungan perpipaan menggunakan perhitungan komputer melalui program Watercad ternyata masih ditemukan kecepatan aliran yang relatif rendah, yang tidak sesuai dengan kriteria pendistribusian air minum bahwa kecepatan minimal dalam pipa sebesar 0,3 $\mathrm{m} / \mathrm{dt}$. Ini bisa dipahami karena diameter pipa yang terpasang saat ini direncanakan untuk sepuluh tahun yang akan datang yang memerlukan debit lebih besar dengan penambahan sambungan rumah baru. Sedangkan untuk tekanan terendah di titik terjauh sebesar 4,1 atmosper (atm) masih sesuai dengan kriteria pendistribusian air minum bahwa tekanan minimal pada titik terjauh sebesar 1 atmosper (atm).

4. Sistem perencanaan

Berdasarkan perhitungan perpipaan menggunakan perhitungan komputer melalui program WaterCad dengan kriteria pendistribusian air minum bahwa kecepatan minimal dalam pipa sebesar $0,3 \mathrm{~m} / \mathrm{dt}$ dan tekanan minimal pada titik terjauh sebesar 1 atmosper (atm), maka untuk melayani kebutuhan debit air sebesar 214,02 pada tahun 2022 diperlukan penggantian pompa dan pemasangan jaringan pipa baru.

\section{Saran}

Dari kesimpulan diatas dapat peneliti sarankan hal-hal berikut ini:

1. Agar penduduk di wilayah Kecamatan Candi tetap mendapat pelayanan air bersih sampai tahun 2022 maka kekurangan debit dapat diambilkan dari pembangunan Proyek Umbulan II yang rencana akan dimulai pada tahun 2013.

2. Titik pengambilan (off take) dapat menggunakan reservoir kapasitas 1000 $\mathrm{M}^{3}$ yang ada di IPA Kedunguling .

3. Agar tekanan dan velocity sesuai dengan kriteria pendistribusian maka perlu dilakukan

a) Pengadaan 3 pompa berkapasitas $120 \mathrm{l} / \mathrm{dt}$ dengan head $80 \mathrm{~m}$, dengan kodisi 2 pompa operasional dan 1 pompa standby.

b) Pengadaan jaringan pipa $p v c$ baru diameter $250 \mathrm{~mm}$ dari reservoir ke arah kota sidoarjo melalui pertigaan Sumokali.

c) Pengadaan jaringan pipa $p v c$ baru diameter $250 \mathrm{~mm}$ dari reservoir ke arah Ngampel Sari melalui Perumahan Prima Sari.

4. Dengan rencana pembangunan Proyek Umbulan II dimana off take Candi akan memperoleh debit sebesar $400 \mathrm{l} / \mathrm{dt}$ maka kelebihan debit tersebut dapat di alirkan untuk memenuhi kebutuhan kota Sidoarjo (suplay kota), sedangkan bangunan pengolahan air (water treatment plant) dapat dipindah ke daerah / kecamatan lain yang belum mendapat layanan air bersih dari PDAM "Delta Tirta" Kabupaten Sidoarjo. 


\section{DAFTAR PUSTAKA}

Bagian Litbang, PDAM "Delta Tirta" Kabupaten Sidoarjo, 2011. Kebutuhan Air Minum dan Tingkat Pelayanan PDAM “Delta Tirta” Kabupaten Sidoarjo.

BPS Kabupaten Sidoarjo. (2010). Kabupaten Sidoarjo dalam angka 2011.

BPS Surabaya. (2007).

USAID, Modul Pelatihan WaterCAD V8, 2009. Pelatihan Analisa Jaringan Menggunakan Software EPANET 2.0 dan Pengenalan Aplikasi Perangkat Lunak WaterCAD.

Dharmasetiawan, Martin, 2004. Sistem Perpipaan Distribusi Air Minum. Ekamitra Engineering, Jakarta.

Departemen Pekerjaan Umum, Dirjen Cipta Karya, 1974. Kebocoran pada Jaringan Distribusi 